\title{
Thermal transport properties in GaAs (110)/GaAs (100) and GaAs/InAs interfaces by Reverse Non-equilibrium Molecular Dynamics
}

\author{
"NENUWE, ON; AGBALAGBA, OE \\ Department of Physics, Federal University of Petroleum Resources, P.M.B. 1221, Effurun, Delta State, Nigeria \\ *Corresponding Author Email: nenuwe.nelson@fupre.edu.ng; Tel: +2438037295834
}

\begin{abstract}
It is well known that the physics of thermal management is quite challenging as electronic device sizes are miniaturized and new materials are developed. This study calculates the thermal interface conductance (TIC), thermal interface resistance (TIR) and thermal grain conductivity across $\mathrm{GaAs}(110) / \mathrm{GaAs}(100)$ and $\mathrm{GaAs} / \mathrm{InAs}$ interfaces using the reverse non-equilibrium molecular dynamics (RNEMD) technique. Data obtained showed that, at $\operatorname{GaAs}(110) / \operatorname{GaAs}(100)$ the TIC increased from $0.912 \times 10^{-9}(\mathrm{~W} / \mathrm{K})$ to $1.433 \times 10^{-9}(\mathrm{~W} / \mathrm{K})$, the TIR decreased from 1.096 $\times 10^{9}(\mathrm{~K} / \mathrm{W})$ to $0.697 \times 10^{9}(\mathrm{~K} / \mathrm{W})$ between $300 \mathrm{~K}$ and $1000 \mathrm{~K}$, and the thermal grain conductivity increased from 7.47 $(\mathrm{W} / \mathrm{mK})$ to $15.52(\mathrm{~W} / \mathrm{mK})$ and $7.48(\mathrm{~W} / \mathrm{mK})$ to $80.71(\mathrm{~W} / \mathrm{mK})$ between $15 \AA$ and $55 \AA$ at $300 \mathrm{~K}$. At GaAs/InAs interface the TIC increased from $7.228 \times 10^{-10}(\mathrm{~W} / \mathrm{K})$ to $14.498 \times 10^{-10}(\mathrm{~W} / \mathrm{K})$ and the TIR decreased from $0.138 \times 10^{10}(\mathrm{~K} / \mathrm{W})$ to $0.068 \times 10^{10}(\mathrm{~K} / \mathrm{W})$ between $300 \mathrm{~K}$ and $700 \mathrm{~K}$, respectively. It was observed that, as temperature is increased the TIC and TIR for both materials change significantly. This trend is consistent with previous molecular dynamic studies of interface materials.
\end{abstract}

\section{DOI:https://dx.doi.org/10.4314/jasem.v23i10.21}

Copyright: Copyright (C) 2019 Nenuwe and Agbalagba. This is an open access article distributed under the Creative Commons Attribution License (CCL), which permits unrestricted use, distribution, and reproduction in any medium, provided the original work is properly cited.

Dates: Received: 01September 2019; Revised: 21 October 2019; 27 October 2019

Keywords: Interface conductance, thermal resistance, grain conductivity, temperature.

The physics of thermal management in micro/nano/ optoelectronics is quite challenging as device sizes are miniaturized and new materials are developed (Goddard et al., 2012; Simon and Alan, 2005; Ferainet al., 2011; Schelling et al., 2005; Nenuwe, 2018). The thermal interface conductance and thermal interface resistance vary significantly depending on the fabrication method and types of materials used for multilayer thin-film devices. Therefore, the determination of these properties between different materials is critical to both the design and selection of new materials and fabrication techniques. Also, understanding the temperature dependence of thermal properties at material interfaces is critical to further engineer thermal conductance in micro/nano/optoelectronic devices. For this purpose, it has become worldwide interest in the study and determination of thermal transport properties of interfaces between different materials. In particular, attention has been given to the investigation of TIC and TIR in: $\mathrm{Ge}_{2} \mathrm{Sb}_{2} \mathrm{Te}_{5} / \mathrm{ZnS}: \mathrm{SiO}_{2}$ interface (Kim and Kwun, 2000), metal-dielectric interfaces (Robert et al., 2005), multilayer thermionic refrigeration (Mahan and Woods, 1998), thin-film high- $\mathrm{T}_{\mathrm{c}}$ superconductivity (Phelan, 1998), AlGaN/ GaN heterostructure field-effect transistors (Filippov and Balandin, 2003), effect of dislocation on thermal boundary conductance across $\mathrm{GaSb} / \mathrm{GaAs}$ interfaces (Patricet al., 2011) and $\mathrm{Cr} / \mathrm{Si}$ interface (Patricet al., 2008). However, there is no information on the thermal interface conductance, thermal interface resistance and thermal grain conductivity of $\mathrm{GaAs}(110) / \mathrm{GaAs}(100)$ and $\mathrm{GaAs} / \mathrm{InAs}$ in the literature. In this study therefore, we use the reverse non-equilibrium molecular dynamics technique to calculate the thermal interface conductance, resistance and thermal grain conductivity across $\mathrm{GaAs}(110) / \mathrm{GaAs}(100)$ and $\mathrm{GaAs} / \mathrm{InAs}$ interfaces.

\section{MATERIALS AND METHODS}

In this work, we used reverse non-equilibrium molecular dynamics method as implemented in QuantumATK 2017.2 for calculating the thermal interface conductance (Muller-Plathe, 1997; Carlos and Avalos, 2003; AtomistixToolKit, 2007). This technique uses an idea of imposing heat flux through the crystal structure under consideration and determining a temperature gradient that builds up as a result of the heat flux imposed. The heat flux is imposed by constantly transferring energy from heat source at one end of the grain to heat sink at the other end of the simulation grain. Then, the thermal interface conductance $(G)$ across the boundary can be calculated from the heat flux $(d Q / d t)$ and temperature 
gradient ( $\Delta T$ ) with the relation $G=(d Q / d t) / \Delta T$. The thermal interface resistance $(R)$ is calculated from $R=1 / G$.

In order to carry out the RNEMD simulation, the QuantumATK is used to generate gallium arsenide (GaAs) and indium arsenide (InAs) crystal grains in the (110) and (100) crystallographic orientations. Then, the two grain boundaries $\operatorname{GaAs}(110) / \mathrm{GaAs}$ (100) and $\operatorname{GaAs}(110) / \operatorname{InAs}(100)$ are created and studied for $19.98 \times 16.96 \times 160$ supercells. The thermal current is directed to run along the $\mathrm{z}$-direction and the supercell is non-periodic in the $C_{z}$-direction so as to terminate the system by vacuum at either end. Then, the slab is centered in the middle of the supercell. In these calculations, Ga-As and In-As bonding interactions have been described by Tersoff potentials (Kristen et al., 2011; Nordlund et al., 2000) and an NPT Martyna-Tobias-Klein ensemble (Martyna et al., 1994) has been used. The systems were initially optimized using LBFGS method (Zhu et al., 1997) with a force tolerance of $0.1 \mathrm{eV} / \mathrm{A}$ and $0.1 \mathrm{GPa}$ in stress error, to remove initial large destabilizing forces that might have occurred during the interface generation. Then, the lateral cell vectors are relaxed and equilibrated to the target temperature. All simulations were carried out at zero pressure.

The thermal transport simulation was first performed at an average temperature of $300 \mathrm{~K}$. The simulation is carried out for $10^{5}$ steps at log interval of 5000. External stress is switched off and Maxwell Boltzmann distribution was used as initial velocity to remove the center of mass momentum. The simulation is carried out at constant temperature and pressure. When the simulation is done, grains of the resulting structure is now relaxed and equilibrated at $300 \mathrm{~K}$.

For the equilibrated structure, regions of heat source and heat sink are defined within the (110) and (100) directions. NVT Nose Hoover Chain (Martyna et al., 1992) type molecular dynamics (MD) is then used to equilibrate the system at constant volume. This is carried out with a time step of 100 femto second (fs) for $10^{5}$ at intervals of 1000 to allow the system to reach a steady-state.

Finally, the non-equilibrium simulation is performed with a time step of 1 fs for $8 \times 10^{5}$ at intervals of 1000 . The exchange interval is allowed to simulate for every 500 steps to increase the transferred kinetic energy per simulation time. This yields larger temperature gradient and a more definite temperature profile. When the simulation is done, the system is carefully checked for convergence with respect to the system size and simulation time. Then, the heat flux $(d Q / d t)$ is read from the log file and the TIC is calculated in units of $\mathrm{W} / \mathrm{K}$ using a Python script. Subsequently, the entire simulation is repeated for other temperatures up to $1000 \mathrm{~K}$ at intervals of $100 \mathrm{~K}$. Also, the grain size dependence of thermal conductivity for $\mathrm{GaAs}(110) / \mathrm{GaAs}(100)$ supercell is modeled by the distance between the interface boundary and five different points.

\section{RESULTS AND DISCUSSION}

For the $\operatorname{GaAs}(110) / \operatorname{GaAs}(100)$ interface, results obtained for heat flux imposed, thermal interface conductance and thermal interface resistance at all simulation temperatures are tabulated in Table 1. At $300 \mathrm{~K}$, a temperature gradient of $\Delta T=150 \mathrm{~K}$ builds up around $C_{z}=77 \AA$ as a result of imposing $0.854 \times 10^{-3}$ $\mathrm{eV} / \mathrm{fs}$ heat flux. This is achieved by continuously transferring energy from the heat source to heat sink. A thermal interface conductance of $0.912 \times 10^{-9} \mathrm{~W} / \mathrm{K}$ was obtained at this temperature. This means that the boundary between the temperature source and sink causes a discontinuity in the temperature profile as the interface provides a thermal resistance of $1.096 \times 10^{9}$ $\mathrm{K} / \mathrm{W}$ to the thermal current.

Table 1. The average heat flux $(d Q / d t)$, thermal interface conductance and thermal interface resistance $(\mathrm{R})$ at different

\begin{tabular}{llll}
\multicolumn{4}{c}{ temperatures for $\mathrm{GaAs}(110) / \mathrm{GaAs}(100)}$. \\
\hline $\mathbf{T}(\mathbf{K})$ & $d Q d t\left(\times 10^{-3}\right)$ & $\mathbf{G}\left(\times 10^{-9}\right)$ & $\mathbf{R}\left(\times 10^{9}\right)$ \\
& $(\mathbf{e V} / \mathbf{f s})$ & $\left(\mathbf{W K}^{-1}\right)$ & $\left(\mathbf{K W}^{-1}\right)$ \\
\hline $\mathbf{3 0 0}$ & 0.854 & 0.912 & 1.096 \\
$\mathbf{4 0 0}$ & 1.206 & 0.970 & 1.030 \\
$\mathbf{5 0 0}$ & 1.459 & 1.011 & 0.989 \\
$\mathbf{6 0 0}$ & 1.745 & 1.063 & 0.941 \\
$\mathbf{7 0 0}$ & 2.075 & 1.108 & 0.902 \\
$\mathbf{8 0 0}$ & 2.409 & 1.118 & 0.894 \\
$\mathbf{9 0 0}$ & 2.720 & 1.128 & 0.886 \\
$\mathbf{1 0 0 0}$ & 2.883 & 1.433 & 0.697 \\
\hline
\end{tabular}

At $400 \mathrm{~K}$, a temperature gradient of $199 \mathrm{~K}$ builds up around $79 \AA$ when a heat flux of $1.206 \times 10^{-3} \mathrm{eV} / \mathrm{fs}$ is imposed. Here, the results obtained for TIC is $0.97 \times 10^{-9} \mathrm{~W} / \mathrm{K}$, and the boundary provides a thermal resistance of $1.03 \times 10^{9} \mathrm{~K} / \mathrm{W}$ to the thermal current. For simulation at $500 \mathrm{~K}$, a temperature gradient of $231 \mathrm{~K}$ builds up around $75 \AA$ due to $1.459 \times 10^{-3} \mathrm{eV} / \mathrm{fs}$ heat flux imposed. The results obtained for thermal interface conductance is $1.011 \times 10^{-9} \mathrm{~W} / \mathrm{K}$, and the interface provides a thermal resistance of $0.989 \times 10^{9}$ $\mathrm{K} / \mathrm{W}$ to the thermal current as it creates a discontinuity in the temperature profile. For simulation at $600 \mathrm{~K}$, a temperature gradient of $260 \mathrm{~K}$ builds up around $75 \AA$ by imposing heat flux of $1.745 \times 10^{-3} \mathrm{eV} / \mathrm{fs}$. Consequently, the results obtained for TIC is $1.063 \times 10^{-9} \mathrm{~W} / \mathrm{K}$ and the thermal interface resistance to the heat flow is $0.941 \times 10^{9} \mathrm{~K} / \mathrm{W}$. At $700 \mathrm{~K}$, a temperature gradient of $300 \mathrm{~K}$ builds up around $73 \AA$ as a result of imposing heat flux of $2.075 \times 10^{-3} \mathrm{eV} / \mathrm{fs}$, 
and the results for TIC and TIR are obtained as $1.108 \times 10^{-9} \mathrm{~W} / \mathrm{K}$ and $0.902 \times 10^{9} \mathrm{~K} / \mathrm{W}$, respectively. Again, this value of thermal interface resistance represents the opposition to thermal current across the boundary between the materials under study at this temperature. Also, at $800 \mathrm{~K}$, by imposing heat flux of $2.409 \times 10^{-3} \mathrm{eV} / \mathrm{fs}$ a temperature gradient of $345 \mathrm{~K}$ builds up around $69 \AA$. Here, the TIC and TIR are calculated to be $1.118 \times 10^{-9} \mathrm{~W} / \mathrm{K}$ and $0.894 \times 10^{9}$ $\mathrm{K} / \mathrm{W}$, respectively. This implies that the thermal current across the materials interface is opposed by $0.894 \times 10^{9} \mathrm{~K} / \mathrm{W}$ amount of TIR. Finally, at $900 \mathrm{~K}$ and $1000 \mathrm{~K}$, heat flux of $2.72 \times 10^{-3} \mathrm{eV} /$ fs and $2.883 \times 10^{-3}$ $\mathrm{eV} / \mathrm{fs}$ are imposed and temperature gradients of $386 \mathrm{~K}$ and $404 \mathrm{~K}$ build up around $75 \AA$ and $71 \AA$, respectively. Thermal interface conductance and thermal interface resistance of $1.128 \times 10^{-9} \mathrm{~W} / \mathrm{K}$ and $0.886 \times 10^{9} / \mathrm{K} / \mathrm{W}$ are respectively obtained for $900 \mathrm{~K}$, and $1.433 \times 10^{-9} \mathrm{~W} / \mathrm{K}$ and $0.697 \times 10^{9} / \mathrm{K} / \mathrm{W}$ for simulation at $1000 \mathrm{~K}$. This shows that the thermal current is opposed by $0.886 \times 10^{9} / \mathrm{K} / \mathrm{W}$ and $0.697 \times 10^{9} / \mathrm{K} / \mathrm{W}$ TIR at these temperatures.

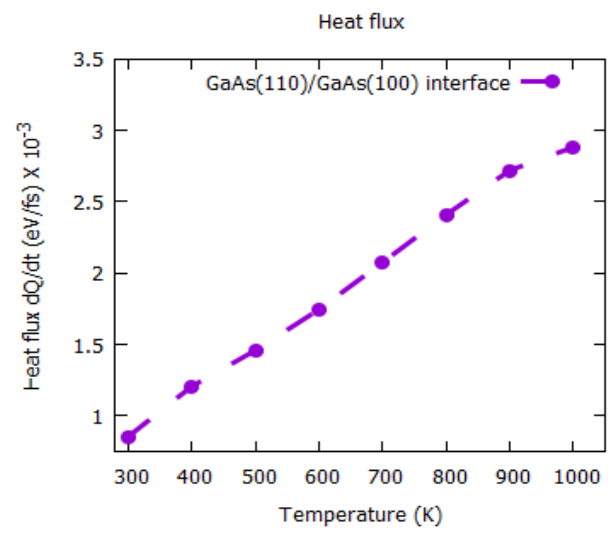

Fig 1. Temperature dependence of heat flux $d Q / d t$ for $\mathrm{GaAs}(110) / \mathrm{GaAs}(100)$ interface

It was observed that the temperature gradient generated for the entire simulation increased from 150 $-404 \mathrm{~K}$. The heat flux is as well observed to increase with increasing temperature as displayed in Figure 1

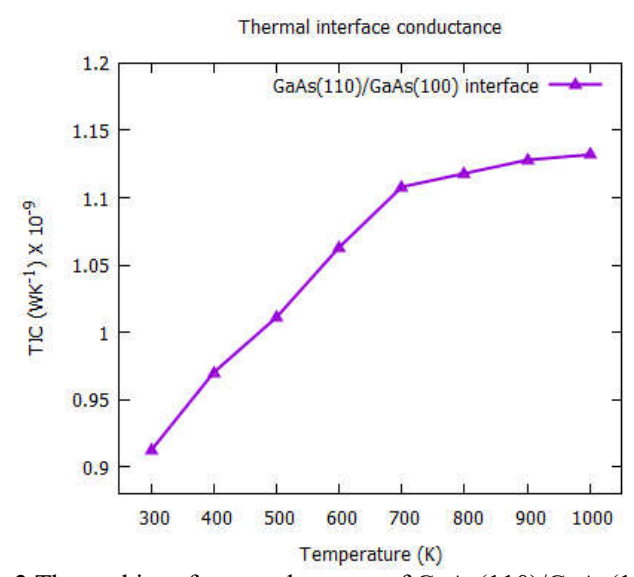

Fig 2. Thermal interface conductance of $\mathrm{GaAs}(110) / \mathrm{GaAs}(100)$ as a function of temperature

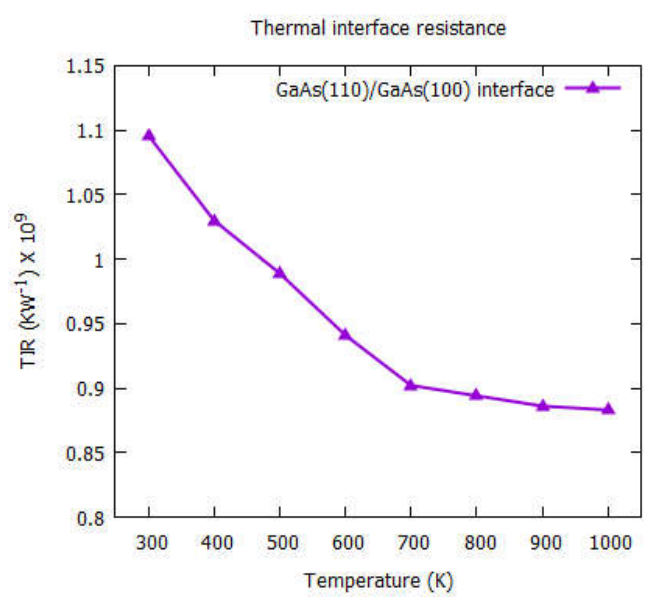

Fig 3. Thermal interface resistance of $\operatorname{GaAs}(110) / \mathrm{GaAs}(100)$ as a function of temperature

The thermal interface resistance creates a barrier to the thermal current leading to temperature gradient across the interface (Kapitza, 1941; Robert et al., 2007). Also, the TIC and TIR are sensitive to temperature. Figures 2 and 3 show the thermal interface conductance and thermal interface resistance for $\mathrm{GaAs}(110) / \mathrm{GaAs}(100)$ as a function of temperature. As the temperature is increased from $300-1000 \mathrm{~K}$, the TIC increased linearly from $0.912 \times 10^{-9}$ to $1.433 \times 10^{-9} \mathrm{~W} / \mathrm{K}$, while the TIR decreases from $1.096 \times 10^{9}$ to $0.697 \times 10^{9} \mathrm{~K} / \mathrm{W}$. This trend has been obtained earlier by Song and Min (2013). This significant property makes GaAs suitable for use as interface materials with other semiconductors in integrated circuit applications, with the aim of proper thermal management across boundaries in micro/nano/optoelectronic devices. 
Table 2. The grain size, temperature gradient $d T / d z$, and thermal conductivity $\kappa$, at $300 \mathrm{~K}$ for (110) and (100) oriented grains.

\begin{tabular}{|c|c|c|c|c|}
\hline & \multicolumn{2}{|c|}{ (110) oriented grains } & \multicolumn{2}{|c|}{ (100) oriented grains } \\
\hline $\begin{array}{l}\text { Grain size } \\
(\AA ̊)\end{array}$ & $\begin{array}{l}d T / d z \\
(K / \AA ̊)\end{array}$ & $\begin{array}{l}\kappa \\
\left(\mathbf{W K}^{-1} \mathbf{m}^{-1}\right)\end{array}$ & $\begin{array}{l}d T / d z \\
(\mathrm{~K} / \AA)\end{array}$ & $\begin{array}{l}\kappa \\
\left(\mathbf{W K}^{-1} \mathbf{m}^{-1}\right)\end{array}$ \\
\hline 15 & -0.5475 & 7.47 & -0.548 & 7.48 \\
\hline 25 & -0.4924 & 8.23 & -0.324 & 12.61 \\
\hline 35 & -0.4606 & 8.77 & -0.221 & 18.34 \\
\hline 45 & -0.3537 & 11.53 & -0.155 & 26.90 \\
\hline 55 & -0.2689 & 15.52 & -0.057 & 80.71 \\
\hline
\end{tabular}

Table 3. The grain size, temperature gradient $d T / d z$, and thermal conductivity $\kappa$, at $400 \mathrm{~K}$ for (110) and (100) oriented grains.

\begin{tabular}{|c|c|c|c|c|}
\hline & \multicolumn{2}{|c|}{ (110) oriented grains } & \multicolumn{2}{|c|}{ (100) oriented grains } \\
\hline $\begin{array}{l}\text { Grain size } \\
\text { (§) }\end{array}$ & $\begin{array}{l}d T / d z \\
(K / \AA)\end{array}$ & $\begin{array}{l}\text { K } \\
\left(\mathbf{W K}^{-1} \mathbf{m}^{-1}\right)\end{array}$ & $\begin{array}{l}d T / d z \\
(\mathbf{K} / \AA)\end{array}$ & $\begin{array}{l}\text { K } \\
\left(\mathbf{W K}^{-1} \mathbf{m}^{-1}\right)\end{array}$ \\
\hline 15 & -1.824 & 3.13 & -0.742 & 7.70 \\
\hline 25 & -1.242 & 4.59 & -0.447 & 12.95 \\
\hline 35 & -0.879 & 6.55 & -0.290 & 19.65 \\
\hline 45 & -0.699 & 8.25 & -0.229 & 25.90 \\
\hline 55 & -0.580 & 9.82 & -0.074 & 81.41 \\
\hline
\end{tabular}

Table 4. The grain size, temperature gradient $d T / d z$, and thermal conductivity $\kappa$, at $500 \mathrm{~K}$ for (110) and (100) oriented grains.

\begin{tabular}{|c|c|c|c|c|}
\hline \multirow[b]{2}{*}{$\begin{array}{l}\text { Grain size } \\
(\AA)\end{array}$} & \multicolumn{2}{|c|}{ (110) oriented grains } & \multicolumn{2}{|c|}{ (100) oriented grains } \\
\hline & $\begin{array}{l}d T / d z \\
(K / \AA ̊)\end{array}$ & $\begin{array}{l}K \\
\left(\mathbf{W K}^{-1} \mathbf{m}^{-1}\right)\end{array}$ & $\begin{array}{l}d T / d z \\
(\mathrm{~K} / \AA \AA)\end{array}$ & $\begin{array}{l}\kappa \\
\left(W^{-1} \mathbf{m}^{-1}\right)\end{array}$ \\
\hline 15 & -1.361 & 5.06 & -1.451 & 4.75 \\
\hline 25 & -1.067 & 6.50 & -0.794 & 8.72 \\
\hline 35 & -0.873 & 7.92 & -0.517 & 13.51 \\
\hline 45 & -0.657 & 10.60 & -0.352 & 19.69 \\
\hline 55 & -0.611 & 11.30 & -0.178 & 40.55 \\
\hline
\end{tabular}

Table 5. The grain size, temperature gradient $d T / d z$, and thermal conductivity $\kappa$, at $600 \mathrm{~K}$ for (110) and (100) oriented grains.

\begin{tabular}{|c|c|c|c|c|}
\hline & \multicolumn{2}{|c|}{ (110) oriented grains } & \multicolumn{2}{|c|}{ (100) oriented grains } \\
\hline $\begin{array}{l}\text { Grain size } \\
\text { (A) }\end{array}$ & $\begin{array}{l}d T / d z \\
(K / \AA))\end{array}$ & $\begin{array}{l}\kappa \\
\left(W^{-1} \mathbf{m}^{-1}\right)\end{array}$ & $\begin{array}{l}d T / d z \\
(\mathbf{K} / \AA)\end{array}$ & $\begin{array}{l}\kappa \\
\left(\mathbf{W K}^{-1} \mathbf{m}^{-1}\right)\end{array}$ \\
\hline 15 & -1.858 & 4.45 & -1.56 & 5.28 \\
\hline 25 & -1.187 & 6.98 & -1.375 & 6.01 \\
\hline 35 & -0.954 & 8.68 & -0.925 & 8.96 \\
\hline 45 & -0.762 & 10.85 & -0.608 & 13.74 \\
\hline 55 & -0.603 & 13.74 & -0.404 & 20.61 \\
\hline
\end{tabular}

Table 6. The grain size, temperature gradient $d T / d z$, and thermal conductivity $\kappa$, at $700 \mathrm{~K}$ for (110) and (100) oriented grains.

\begin{tabular}{|c|c|c|c|c|}
\hline \multirow[b]{2}{*}{$\begin{array}{l}\text { Grain size } \\
(\AA))\end{array}$} & \multicolumn{2}{|c|}{ (110) oriented grains } & \multicolumn{2}{|c|}{ (100) oriented grains } \\
\hline & $\begin{array}{l}d T / d z \\
(K / \AA)\end{array}$ & $\begin{array}{l}K \\
\left(\mathbf{W K}^{-1} \mathbf{m}^{-1}\right)\end{array}$ & $\begin{array}{l}d T / d z \\
(\mathrm{~K} / \AA)\end{array}$ & $\begin{array}{l}K \\
\left(\mathbf{W K}^{-1} \mathbf{m}^{-1}\right)\end{array}$ \\
\hline 15 & -0.92 & 10.65 & -1.68 & 5.83 \\
\hline 25 & -0.961 & 10.21 & -1.068 & 9.25 \\
\hline 35 & -1.056 & 9.33 & -0.772 & 12.73 \\
\hline 45 & -0.875 & 11.27 & -0.585 & 16.90 \\
\hline 55 & -0.722 & 13.61 & -0.406 & 24.51 \\
\hline
\end{tabular}

Also, we calculated the grain size dependence of thermal conductivity for the (100) and (110) crystallographic directions. For the $\operatorname{GaAs}(110) / \operatorname{GaAs}(100)$ supercell, the grain size dependence of thermal conductivity is displayed in Tables $2-9$. The thermal conductivity calculated for $300-1000 \mathrm{~K}$ at different grain sizes. It can be seen from the tables that thermal conductivity is sensitive to grain size and temperature. For the (100) and (110) grains, at all simulated temperatures, thermal conductivity increased monotonically between 15 - $55 \AA$. However, the values obtained for the (100) orientation are observed to be higher than the results obtained for (110) at all temperatures except at $700 \mathrm{~K}$. This might be as a result of the fact that beyond this interface the $\mathrm{GaAs}(100)$ grains offer lower grain thermal resistance to the thermal current. In the same vein, the heat flux imposed, temperature gradient, TIC and TIR simulated at $300 \mathrm{~K}-700 \mathrm{~K}$ for GaAs/InAs interface are displayed in Table 10. At $300 \mathrm{~K}$ a temperature gradient of $172 \mathrm{~K}$ builds up as a result of imposing $0.776 \times 10^{-3} \mathrm{eV} / \mathrm{fs}$ heat flux, and a TIC of $7.228 \times 10^{-10} \mathrm{~W} / \mathrm{K}$ was obtained. Here, the boundary between the heat source and heat sink causes a discontinuity in the temperature profile by providing a thermal resistance of $0.138 \times 10^{-10}$ $\mathrm{K} / \mathrm{W}$ to the heat current. Similarly, at $400,500,600$, and $700 \mathrm{~K}$, temperature gradients of $\Delta T=191$, 232, 239 and $245 \mathrm{~K}$ builds up as a result of imposing heat flux of 1.111, $1.353,1.72$ and $2.217 \mathrm{eV} / \mathrm{fs}$. The thermal interface conductance calculated at these temperatures are respectively $(9.3,9.341,11.53$ and 14.498) $\mathrm{X} 10^{-3} \mathrm{~W} / \mathrm{K}$. This implies that, the boundary between the heat source and heat sink causes discontinuity in the temperature profile as the interface provides thermal resistance of $0.108 \times 10^{10}$, $0.107 \times 10^{10}, 0.086 \times 10^{10}$ and 0.068 $\mathrm{X} 10^{10} \mathrm{~K} / \mathrm{W}$ to the thermal current. Again, it was observed that the heat flux, thermal interface conductance and thermal interface resistance are sensitive to temperature as shown in Figures 5, 6 and 7, respectively. As temperature is increased from $300-$ $700 \mathrm{~K}$, the heat flux also increased from $0.776 \times 10^{-3}-2.217 \times 10^{-3}$ $\mathrm{eV} / \mathrm{fs}$, and the TIC increased from $7.228 \times 10^{-10}-14.498 \times 10^{-10} \mathrm{~W} / \mathrm{K}$. While, the TIR was observed to decrease from $0.138 \times 10^{10}-0.068$ $\mathrm{X} \quad 10^{10} \mathrm{~W} / \mathrm{K}$ with increasing temperature 
Table 7. The grain size, temperature gradient $d T / d z$, and thermal conductivity $\kappa$, at $800 \mathrm{~K}$ for (110) and (100) oriented grains.

\begin{tabular}{|c|c|c|c|c|}
\hline \multirow[b]{2}{*}{$\begin{array}{l}\text { Grain size } \\
\text { (§̊) }\end{array}$} & \multicolumn{2}{|c|}{ (110) oriented grains } & \multicolumn{2}{|c|}{ (100) oriented grains } \\
\hline & $\begin{array}{l}d T / d z \\
(K / \AA)\end{array}$ & $\begin{array}{l}K \\
\left(\mathbf{W K}^{-1} \mathbf{m}^{-1}\right)\end{array}$ & 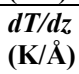 & $\begin{array}{l}\kappa \\
\left(\mathbf{W K}^{-1} \mathbf{m}^{-1}\right)\end{array}$ \\
\hline 15 & -2.100 & 5.42 & -1.827 & 6.25 \\
\hline 25 & -1.316 & 8.69 & -1.219 & 9.40 \\
\hline 35 & -1.372 & 8.30 & -1.019 & 11.27 \\
\hline 45 & -1.169 & 9.81 & -0.694 & 16.49 \\
\hline 55 & -0.940 & 12.11 & -0.465 & 25.29 \\
\hline
\end{tabular}

Table 8. The grain size, temperature gradient $d T / d z$, and thermal conductivity $\kappa$, at $900 \mathrm{~K}$ for (110) and (100) oriented grains.

\begin{tabular}{|c|c|c|c|c|}
\hline \multirow[b]{2}{*}{$\begin{array}{l}\text { Grain size } \\
\text { (§) }\end{array}$} & \multicolumn{2}{|c|}{ (110) oriented grains } & \multicolumn{2}{|c|}{ (100) oriented grains } \\
\hline & $\begin{array}{l}d T / d z \\
(K / \AA ̊)\end{array}$ & $\begin{array}{l}K \\
\left(\mathbf{W K}^{-1} \mathbf{m}^{-1}\right)\end{array}$ & $\begin{array}{l}d T / d z \\
(K / \AA ̊)\end{array}$ & $\begin{array}{l}\text { K } \\
\left(\mathbf{W K}^{-1} \mathbf{m}^{-1}\right)\end{array}$ \\
\hline 15 & -2.67 & 4.81 & -2.218 & 5.81 \\
\hline 25 & -2.25 & 5.71 & -1.387 & 9.31 \\
\hline 35 & -1.96 & 6.55 & -0.934 & 13.82 \\
\hline 45 & -1.71 & 7.51 & -0.803 & 16.06 \\
\hline 55 & -1.35 & 9.52 & -0.562 & 22.95 \\
\hline
\end{tabular}

Table 9. The grain size, temperature gradient $d T / d z$, and thermal conductivity $\kappa$, at $1000 \mathrm{~K}$ for $(110)$ and $(100)$ oriented grains.

\begin{tabular}{|c|c|c|c|c|}
\hline \multirow[b]{2}{*}{$\begin{array}{l}\text { Grain size } \\
(\AA)\end{array}$} & \multicolumn{2}{|c|}{ (110) oriented grains } & \multicolumn{2}{|c|}{ (100) oriented grains } \\
\hline & $\begin{array}{l}d T / d z \\
(K / \AA \AA)\end{array}$ & $\begin{array}{l}K \\
\left(\mathbf{W K}^{-1} \mathbf{m}^{-1}\right)\end{array}$ & $\begin{array}{l}d T / d z \\
(\mathrm{~K} / \AA \AA)\end{array}$ & $\begin{array}{l}K \\
\left(\mathbf{W K}^{-1} \mathbf{m}^{-1}\right)\end{array}$ \\
\hline 15 & -2.538 & 5.38 & -2.236 & 6.10 \\
\hline 25 & -2.54 & 5.36 & -1.649 & 8.30 \\
\hline 35 & -2.19 & 6.22 & -1.281 & 10.64 \\
\hline 45 & -1.80 & 7.56 & -0.945 & 14.49 \\
\hline 55 & -1.45 & 9.39 & -0.655 & 20.96 \\
\hline
\end{tabular}

Table 10. The average heat flux $(d Q / d t)$, thermal interface conductance and thermal interface resistance $(\mathrm{R})$ at different temperatures for $\mathrm{GaAs}(110) / \operatorname{InAs}(100)$.

\begin{tabular}{|c|c|c|c|c|}
\hline $\begin{array}{l}\mathbf{T} \\
\text { (K) }\end{array}$ & $\underset{(\mathrm{eV} / \mathrm{fs})}{d Q / d t}\left(\times 10^{-3}\right)$ & $\underset{(\mathbf{K})}{\Delta T}$ & $\begin{array}{l}\mathbf{G} \\
\left(\times 10^{-10}\right) \\
\left(\mathbf{W K}^{-1}\right)\end{array}$ & $\begin{array}{l}\mathbf{R} \\
\left(\times 10^{10}\right) \\
\left(\mathrm{KW}^{-1}\right)\end{array}$ \\
\hline 300 & 0.776 & 172 & 7.228 & 0.138 \\
\hline 400 & 1.111 & 191 & 9.300 & 0.108 \\
\hline 500 & 1.353 & 232 & 9.341 & 0.107 \\
\hline 600 & 1.720 & 239 & 11.530 & 0.086 \\
\hline 700 & 2.217 & 245 & 14.498 & 0.068 \\
\hline
\end{tabular}

Conclusion: In this paper, we have used the RNEMD method to carry out the study of thermal transport properties across GaAs(110)/ $\mathrm{GaAs}(100)$ and $\mathrm{GaAs} / \mathrm{InAs}$ interfaces. Results obtained show that the thermal interface conductance increases with increasing temperature, while thermal interface resistance decreases with increasing temperature for both materials. Also, the conductivity was observed to be sensitive to temperature and grain size. Adequate knowledge of these transport properties will always find useful applications in the thermal management of micro/nano/optoelectronic devices.

Acknowledgement: The authors acknowledge the Federal University of Petroleum Resources Effurun for providing the Mini Workstation used for the calculations and also QuantumATK for access to the VNL-ATK software package.

\section{REFERENCES}

AtomistixToolKit 2017.2,

Quantumwise A/S,

www.quantumwise.com.

Carlos, N; Avalos, JB (2003). Nonequilibrium exchange algorithm for molecular dynamics simulation of heat flow in multicomponent systems. Mol. Phys. 101(14): 2303 - 2307.

Ferain, I; Colinge, CA; Colinge, J (2011). Multigate transistors as the future of classical metaloxide-semiconductor field-effect transistors. Nature, 479: $310-$ 316.

Filippov, KA; Balandin, AA (2003). The Effect of the Thermal Boundary Resistance on SelfHeating of $\mathrm{AlGaN} / \mathrm{GaN}$ HFETs. MRS Internet J. Nitride Semicond. Res. 8: E4.

Goddard, W; Brenner, D; Lyslevski, S; Lafrate, G (2012). NanoScience, Engineering and Technology, $3^{\text {rd }}$ ed. Boca Raton: CRC Press.

Kim, EK; Kwun, SI (2000). Thermal boundary resistance at $\mathrm{Ge}_{2} \mathrm{Sb}_{2} \mathrm{Te}_{5} / \mathrm{ZnS}: \mathrm{SiO}_{2}$ interface. Appl. Phys. Lett., 76: 3864 3866.

Mahan, DG; Woods, LM (1998). Multilayer Thermionic Refrigeration. Phys. Rev. Lett. 80: 4016.

Müller-Plathe, F (1997). A simple nonequilibrium molecular dynamics method for calculating the thermal conductivity. $J$. Chem. Phys. 106(14): 6082 6085.

Kapitza, PL (1941). Heat Transfer and Superfluidity of Helium II. Phys. Rev. 60: 354-358. 
Kristen, AF; Yegesh, T; Thomas, H; Peter, K; Matthias, S (2011). Analytic many-body potential for GaAs(001) homoepitaxy: Bulk and surface properties. Phys. Rev. B 83: 195328-1 195328-10.

Martyna, GJ; Klein, ML; Tuckerman, M (1992). Nosé-hoover chains: The canonical ensemble via continuous dynamics. J. Chem. Phys. 97 (4): 2635-2643.

Martyna, GJ; Tobias, DJ; Klein, ML (1994). Constant pressure molecular dynamics algorithms. $J$. Chem. Phys., 101 (5):4177-4189.

Nenuwe, ON (2018). Theoretical investigation of temperature and grain size dependence of thermal properties of alpha-silicon crystal. Covenant $J$. Phys. \& Life Sc. 6(1): $64-76$.

Nordlund, K; Nord, J; Frantz, J; Keinonen, J (2000). Strain-induced Kirkendall mixing at semiconductor interfaces. Comp. Mater. Sc., 18(3-4): 283-294.

Patric, EH; John, CD; Stephen, PC; Christopher, PH; Thomas, JR; Leslie, MP; Ganesh, B (2011). Effect of dislocation density on thermal boundary conductance across $\mathrm{GaSb} / \mathrm{GaAs}$ interface. Appl. Phys. Lett. 98: 161913.

Patric, EH; Pamela, MN; Robert, JS; Thomas, EB; Samuel, G (2008). Influence of interfacial mixing on thermal boundary conductance across $\mathrm{Cr} / \mathrm{Si}$ interface. J. Hea Trans., 130: 062402-1 - 06240210.
Phelan PE (1998). Application of Diffuse Mismatch Theory to the Prediction of Thermal Boundary Resistance in Thin-Film High-Tc Superconductors. ASME. J. Heat Trans.120(1): $37-43$.

Robert, JS; Andrew, NS; Pamela, MN (2005). Measurement of thermal boundary conductance of a series of metal-dielectric interfaces by the transient thermo reflectance technique. J. Heat Trans. 127: $315-322$.

Robert, JS; Leonid, VZ; Norris, PM (2007). Effects of temperature and disorder on thermal boundary conductance at solid-solid interfaces: Nonequilibrium molecular dynamics simulations. Int. J. Heat \& Mass Trans. 50: 3977-3989.

Simon, RP; Alan, JHM (2005). Introduction to Thermal Transport, Elsevier Mater.Today: 18 20 .

Schelling, PK; Shib, L; Goodson, KE (2005). Managing heat for electronics, Mater.Today 8(6): $30-35$.

Song, G; Min, C (2013). Temperature dependence of thermal resistance at a solid/liquid interface. Int. J. Interface Chem. \& Phys., 111: 903-908.

Zhu, C; Byrd, RH; Lu, P; Nocedal, J (1997). Algorithm 778: L-BFGS-B: Fortran subroutines for large-scale bound-constrained optimization. ACM Trans. Mathematical Software 23 (4), 550 560. 